Japan. J. Med. Sci. Biol., 22, 235-252, 1969

\title{
STUDIES ON THE LOCAL IMMUNITY OF INTESTINAL TRACT OF CHICKENS AFTER ORAL ADMINISTRATION OF NEWCASTLE DISEASE VIRUS
}

\author{
REISAKu KONO, YORIYUKI AKAO, AKIRA SASAGAWA \\ AND YOSHITOSHI NOMURA* \\ Central Virus Diagnostic Laboratory, National Institute of Health, \\ Nakato, Murayama-machi, Tokyo 190-12, Japan \\ * Nippon Institute for Biological Science, Tokyo
}

(Received: July 21st, 1969)

\begin{abstract}
SUMMARY : An enterotropic avirulent Newcastle disease virus (NDV-Ishii) which was administered by the oral route in a dose of about $10^{5}-10^{8} \mathrm{TCD}_{50} /$ chick caused alimentary tract infection in 4 week old chickens, which excreted NDV-Ishii in feces from 3 to 7 days after the first feeding. Indirect fluorescent antibody microphotograph of sections of the small intestine revealed that a sort of surface infection was established by the oral administration of enterotropic NDV. But the virus was scarcely recovered from feces after the second feeding 4 to 6 weeks later and the neutralizing activity of fecal extracts, probably coproantibody, was demonstrated a few weeks after the virus feeding. Bursectomy plus $\gamma$ ray irradiation $(650 \mathrm{r})$ after hatching exerted a profound influence on humoral immunity, namely, suppression of HI antibody production in serum, and at the same time the development of local immunity of the alimentary tract was disturbed. Those chickens excreted the virus even after its second administration. On the other hand, thymectomy plus $r$ ray irradiation or $\gamma$ ray irradiation alone had no suppressive effect on establishment of the alimentary tract resistance to reinfection. Therefore it is concluded that the local immunity of the alimentary tract of chickens against refeeding of the enterotropic NDV depends largely on humoral immunity governed by the bursa-dependent lymphoid system, and probably on IgA antibody which is produced locally by lymphoid cells of the lamina propria.
\end{abstract}

\section{INTRODUCTION}

Lipton and Steigman (1963) and our group (Kawakami et al. 1966, Kono et al. 1966) studied the nature of alimentary tract resistance against poliovirus which appeared after the natural infection or the feeding of live poliovirus vaccine, and found an occurrence of coproantibody against poliovirus in feces of patients or vaccinees, concluding that it might contribute to the local immunity. However, there have been arguments on this point because of the irregularity of coproantibody in its appearence (Sabin, 1959, Godfredsen, 1960).

Consequently, we thought it necessary to establish an animal experimental system to elucidate the problem of alimentary tract resistance in intestinal viral

甲野礼作・赤尾頼幸・篠川旦（国立予防衛生研究所ウイルス中央検査部）

野村吉利（日本生物科学研究所） 
infection, and recently succeeded in establishing an alimentary tract infection of chickens, with an enterotropic strain of Newcastly disease virus (NDV) as a desirable experimental model. The present report concerns itself with the animal experiments using the system mentioned above, and discusses the nature of local immunity of the alimentary tract based on the experimental results.

\section{Materials AND Methods}

Virus: NDV-Ishii strain, which was originally isolated from a chicken diagnosed as infectious coryza in Japan, 1962 (Shimizu et al. 1966), was used throughout the experiments. As shown in the experimental results, it is an avirulent strain that has the capacity to multiply well in the alimentary tract.

NDV-Miyadera strain that is a representative of Japanese virulent NDV was employed in some experiments.

Both strains were propagated by the allantoic sac inoculation of 10 day-old chick embryos, and used as infected allantoic fluid harvested $48 \mathrm{hr}$ later.

Chickens: Young chickens of White Leghorn or Rock-Horn* were purchased from a breeding farm where an epizootic of NDV had never been recorded, and were used in most of the experiments. For experiment IV we obtained fertile hen's eggs from the same farm, and hatched them in an egg incubator at $39 \mathrm{C}$ in this laboratory.

Anti NDV sera: Anti NDV-Ishii rabbit serum was prepared in this laboratory, and used for fluorescent antibody staining and identification of the isolated agents. Complement fixation test (CF) titer was 1:256 against S-antigen and 1:512 against $\mathrm{V}$-antigen, and hemagglutination inhibition test (HI) titer was $1: 1024$.

The anti NDV chicken serum used in experiment IV was obtained from a chicken which survived virulent NDV infection and in addition received a booster inoculation of killed NDV vaccine. HI test titer was 1:640 and neutralization test (NT) titer was $1: 1024$ against $100 \mathrm{TCD}_{50}$ of NDV-Ishii.

Administration of NDV: Primary infection of chickens was usually induced at four weeks of age, and the secondary inoculation was done 4 to 6 weeks later. 0.5 to $2.0 \mathrm{ml}$ of NDV suspension was introduced through a rubber tubing inserted into oesophagus of chickens.

In experiment I, chickens whose water supply was suspended for $24 \mathrm{hr}$, were allowed to drink 10 to $14 \mathrm{ml}$ of drinking water containing an appropriate amount of NDV, but that procedure was not adopted in other experiments, since the virus dose delivered was considered inaccurate.

Chick embryo fibroblast (CEF) tube culture: Eight to ten day old chick embryos were harvested and digested with $0.25 \%$ trypsin for $1 \mathrm{hr}$ at $37 \mathrm{C}$, and it was filtered through sterile gauze layers. The cell suspension was washed three times with phosphate buffered saline (PBS) and spun down at $800 \mathrm{rpm}$ for 10 minutes. A $0.3 \% \mathrm{CEF}$ suspension was made with growth medium which was composed of lactalbumin-Earle's solution and $10 \%$ calf serum. Then, $1 \mathrm{ml}$ of the cell suspension was distributed in test tubes, and they were incubated at $37 \mathrm{C}$ for 1 day. The growth medium was changed with maintenance medium, that is, medium 199 plus

* Rock-Horn: Hybrid between Plymouth Rock and White Leghorn. 
$2 \%$ calf serum. The CEF culture tubes were used for NDV isolation and neutralizing antibody titration.

Virus isolation from feces and autopsy materials: The materials were stored at $-70 \mathrm{C}$ until used. They were emulsified in a sterile mortar with lactalbuminEarle's solution plus streptomycin $(1 \mathrm{mg} / \mathrm{ml})$ and penicillin (500 units/ml), and spun down at $8,000 \mathrm{rpm}$ for 15 minutes. One-tenth $\mathrm{ml}$ of the supernate was inoculated into two to four CEF tube cultures. After incubation for 5 days at $37 \mathrm{C}, 0.5 \mathrm{ml}$ of the tissue culture fluid was transferred to test tube and $0.5 \mathrm{ml}$ of $0.5 \%$ chicken red blood cell suspension was added to each tube; they were kept standing for 60 minutes at room temperature. The positive hemagglutination was taken as a sign of successful virus isolation, and the isolates were identified as NDV by HI test using anti NDV rabbit serum.

Hemagglutination inhibition test $(H I)$ : HI was performed with microtiter; $0.025 \mathrm{ml}$ of serially diluted serum and 4 units of antigen (NDV-Ishii) and $0.05 \mathrm{ml}$ of a $0.5 \%$ chicken red blood cell suspension were employed. The plates were kept at room temperature for 30 minutes and the HI titers were read by the sedimentation pattern of red blood cells; the highest dilution of serum giving complete HI was taken as HI titer.

Neutralization test (NT) of sera, tissue extract of alimentary tract, and feces: All the materials were inactivated by heating at $56 \mathrm{C}$ for 30 minutes. They were serially diluted in two-fold steps, and a constant amount of $100 \mathrm{TCD}_{50} / 0.1 \mathrm{ml}$ was added and mixed well in each tube. The dilution of fecal suspension started from $1: 2$ or $1: 3$. The mixtures were kept for one hr at $37 \mathrm{C}$, then overnight at $4 \mathrm{C}$, and $0.2 \mathrm{ml}$ was inoculated into each $\mathrm{CEF}$ culture tube. Final reading was done after five to six days' incubation at $37 \mathrm{C}$, when the virus control showed $100 \mathrm{TCD}_{50}$. In order to determine neutralizing activity titer of the intestinal tissue, the autopsied chicken was thoroughly perfused with prewarmed phosphate buffer saline (PBS) through the left ventricle until the blood was mostly replaced with PBS in the mesentric blood vessels, and then an intestinal tube about $5 \mathrm{~cm}$ long was cut out at the upper, middle and lower portions of the small intestine. Each portion with its contents was weighed, emulsified with an appropriate amount of PBS to make a $50 \%$ emulsion. After centrifugation at $8,000 \mathrm{rpm}$ for 15 minutes the supernate was used as a two-fold diluted extract of intestinal tissue.

Indirect fluorescent antibody staining: Frozen sections of the infected chicken tissues were prepared by cryostat and fixed in acetone for 10 minutes at room temperature. Anti NDV-Ishii rabbit serum, whose complement fixation titer has been described, was absorbed with chicken liver powder and then was employed as the primary serum in a dilution of 1:64. Anti-rabbit globulin goat serum labeled with fluorescein isothiocyanate was generously given by Dr. A. Kawamura and used as the secondary serum in a dilution of $1: 8$.

Bursectomy, thymectomy and $\gamma$ ray irradiation: Bursectomy and/or thymectomy were surgically performed within $24 \mathrm{hr}$ after hatching according to the method described by Peterson et al. (1964). On the next day the chickens were irradiated with Hitachi ${ }^{60} \mathrm{Co} \gamma$ ray irradiation apparatus the dose rate of which was $126 \mathrm{r}$ per minutes for 55 minutes at a distance of $50 \mathrm{~cm}$, namely, the total dose was $650 \mathrm{r}$.

Immunoelectrophoresis: $1.5 \%$ Noble agar in Na barbiturate buffer, $\mathrm{pH} 8.2$, 
$\mu=0.025$, was poured onto and solidified on a glass plate $\left(102 \times 82 \mathrm{~mm}^{2}\right)$ in $1.5 \mathrm{~mm}$ thick. Electrophoresis was performed with $\mathrm{Na}$ barbiturate buffer, $\mathrm{pH} 8.2, \mu=0.05$ and electric current $30 \mathrm{~mA}$ for 1.5 hours at room temperature (Scheidegger, 1959). Equal amount of antichicken globulin rabbit serum which was given by the courtesy of Dr. Ohgimoto were mixed and applied as antiserum in the through.

\section{EXPERIMENTAL RESULTS}

\section{Preliminary Experiment on the Fecal Viral Excretion, Viremia and Resistance after the First Virus Feeding}

Five chickens, 4 weeks old, were inoculated orally with $10^{5.8} \mathrm{TCD}_{50} /$ chick of NDV-Ishii strain to ascertain its multiplication in the alimentary tract. Their feces were collected every other day for a week, and tested for virus by CEF tube cultures.

As shown in Table 1, NDV-Ishii was excreted from 3 to 7 days post challenge and the excreted dose reached $10^{4.5}$ to $10^{7.5} \mathrm{TCD}_{50} / \mathrm{gm}$ of feces.

Table 1. Recovery of NDV-Ishii from feces of the chickens orally inoculated

\begin{tabular}{ccccc}
\hline \multirow{2}{*}{ No. of chicken } & \multicolumn{5}{c}{ Days post challenge } \\
\cline { 2 - 5 } & 1 & 3 & 5 & 7 \\
\hline 1 & $<1$ & $5.5^{*}$ & 6.5 & $<1$ \\
2 & $<1$ & $<1$ & 4.5 & 5.5 \\
3 & $<1$ & 7.5 & 4.5 & 4.5 \\
4 & $<1$ & $<1$ & 6.5 & $<1$ \\
5 & $<1$ & 5.5 & 4.5 & $<1$ \\
\hline
\end{tabular}

${ }^{*} \log \mathrm{TCD}_{50} / \mathrm{gm}$ of feces.

Two of them were challenged by oral administration with $10^{7.0} \mathrm{TCD}_{50}$ of virulent NDV, Miyadera strain, 5 weeks after the primary infection. They were resistant and survived, but the control chickens infected primarily with NDVMiyadera revealed over $80 \%$ fatality. Viremia was checked for ten days after inoculation of NDV-Ishii and for 14 days after the secondary Miyadera strain inoculation, with positive results being never demonstrated.

These preliminary results indicate that NDV-Ishii strain which is introduced by the oral route has a special characteristic of being excreted in stools without causing viraemia, so that it probably is confined to multiplication in the alimentary tract but confers local and generalized immunity to reintroduction of virulent NDV.

\section{Tissue and Organ Tropisms of NDV-Ishii and NDV-Miyadera Strains}

In order to make clear the multiplication sites and tropism of NDV-Ishii strain, fourteen chicken, 4 weeks old, were inoculated with $10^{7.5} \mathrm{TCD}_{50} /$ chick of NDVIshii strain. Two each were sacrificed on day $1,3,5$, and 7 , respectively, after the primary inoculation; six were killed in a similar way on day 3,5 and 7 after 
rechallenged at 8 weeks of age with $10^{6.5} \mathrm{TCD}_{50} /$ chick of the same virus.

As a control, $10^{7.5} \mathrm{TCD}_{50} /$ chick of NDV-Miyadera strain was inoculated by the oral route into 14 chickens, 4 weeks old. All became ill and six of them died spontaneously. Two at a time were autopsied on days $1,3,5$ and 7 .

Reisolation of NDV was performed by CEF tube culture on tissue and organ extracts from autopsied chickens which were primarily infected (Table 2). The results showed that NDV-Miyadera strain was distributed more widely throughout the body, multiplied well in the upper respiratory mucosa but rather poorly in the intestinal tracts, and was recovered from the spleen. On the other hand,

Tabie 2. Distribution of avirulent NDV-Ishii and virulent NDV-Miyadera strains in the viscera of chickens after the primary oral administration

\begin{tabular}{|c|c|c|c|c|c|c|c|c|}
\hline \multirow{3}{*}{$\begin{array}{l}\text { Organ and } \\
\text { tissue extracts }\end{array}$} & \multicolumn{4}{|c|}{$\begin{array}{c}\text { NDV-Ishii } \\
10^{7.5} \mathrm{TCD}_{50} / \text { chick }\end{array}$} & \multicolumn{4}{|c|}{$\begin{array}{l}\text { NDV-Miyadera } \\
10^{7.5} \mathrm{TCD}_{50} / \text { chick }\end{array}$} \\
\hline & \multicolumn{4}{|c|}{ Day } & \multicolumn{4}{|c|}{ Day } \\
\hline & 1 & 3 & 5 & 7 & 1 & 3 & 5 & 7 \\
\hline \multirow{2}{*}{ Larynx and pharynx } & -* & - & - & $1.5^{* *}$ & $>2.0$ & $>4.0$ & 1.5 & - \\
\hline & 0.5 & - & - & 1.5 & - & 2.0 & 3.0 & - \\
\hline \multirow{2}{*}{ Trachea } & - & - & - & - & - & 2.0 & 3.5 & - \\
\hline & - & $>2.0$ & - & - & - & 4.0 & 4.0 & - \\
\hline \multirow{2}{*}{ Oesophagus } & - & 2.0 & - & - & - & 1.5 & 4.0 & 1.5 \\
\hline & - & - & - & - & - & - & 3.5 & - \\
\hline \multirow{2}{*}{ Preventricules } & - & - & - & - & - & 2.5 & 3.5 & - \\
\hline & - & - & - & - & - & - & 2.0 & - \\
\hline \multirow{2}{*}{ Duodenum } & - & - & - & - & - & 1.5 & 1.0 & - \\
\hline & - & - & - & 1.5 & - & - & 1.0 & - \\
\hline \multirow{2}{*}{$\begin{array}{l}\text { Upper portion of the } \\
\text { small Intestine }\end{array}$} & - & - & - & - & - & - & 2.5 & - \\
\hline & - & 5.2 & - & - & - & - & 1.5 & - \\
\hline \multirow{2}{*}{$\begin{array}{l}\text { Middle portion of the } \\
\text { small Intestine }\end{array}$} & - & 4.4 & - & - & - & - & 2.5 & - \\
\hline & - & - & - & - & - & - & - & - \\
\hline \multirow{2}{*}{$\begin{array}{l}\text { Lower portion of the } \\
\text { small Intestine }\end{array}$} & - & 0.5 & 3.5 & 4.5 & - & 2.0 & 2.0 & - \\
\hline & - & 8.2 & - & - & - & 4.0 & 3.5 & - \\
\hline \multirow{2}{*}{ Cecum } & - & 5.5 & - & - & - & 2.0 & 2.0 & - \\
\hline & - & 3.5 & - & - & - & 4.0 & 2.5 & - \\
\hline \multirow{2}{*}{ Rectum } & - & $>6.0$ & - & - & - & 2.0 & 2.0 & - \\
\hline & - & 4.5 & - & - & - & 4.5 & 1.5 & - \\
\hline \multirow{2}{*}{ Spleen } & - & - & - & - & - & - & 3.5 & - \\
\hline & - & - & - & - & - & 2.5 & 3.5 & - \\
\hline
\end{tabular}

* Minus means no virus isolation.

** Figures indicate $\log \mathrm{TCD}_{50} / \mathrm{gm}$ of feces. 
Table 3. Virus titers of intestinal tissue extracts ond occurrence of NDV

\begin{tabular}{|c|c|c|c|}
\hline \multirow{2}{*}{ Tissues } & \multirow{2}{*}{ Items of examination } & \multicolumn{2}{|c|}{ Day post } \\
\hline & & \multicolumn{2}{|c|}{1} \\
\hline \multirow{2}{*}{ Duodenum } & Virus titer & $<1^{*}$ & ND \\
\hline & Specific fluorescence & - & N D \\
\hline \multirow{2}{*}{$\begin{array}{l}\text { Upper portion of the } \\
\text { small intestine }\end{array}$} & Virus titer & $<1$ & $<1$ \\
\hline & Specific fluorescence & 1 & - \\
\hline \multirow{2}{*}{$\begin{array}{l}\text { Middle portion of the } \\
\text { small intestine }\end{array}$} & Virus titer & $<1$ & $<1$ \\
\hline & Specific fluorescence & - & - \\
\hline \multirow{2}{*}{$\begin{array}{l}\text { Lower portion of the } \\
\text { small intestine }\end{array}$} & Virus titer & $<1$ & $<1$ \\
\hline & Specific fluorescence & - & - \\
\hline
\end{tabular}

Two chickens were examined at a time by the indicated day.

* Figures indicate $\log \mathrm{TCD}_{50} / \mathrm{gm}$ of feces.

ND: Not done.

NDV-Ishii strain tended to occur in the intestinal tracts in higher infectivity titers but no virus was found in the spleen and its titer in the tissues of the respiratory tract was lower. These results confirmed the previous reports: one characterizing NDV-Ishii strain (Shimizu et al., 1966) and the other on virulent NDV (Kohn, 1959).

Frozen sections of the small intestine of infected chickens with NDV-Ishii strain were made, and experiments were carried out to stain NDV antigen in the sections with the indirect method of fluorescent antibody staining. Six chickens which were rechallenged with NDV-Ishii strain were included in the fluorescent antibody study and also virus isolation was performed on contents of the bowels of chickens at the same time.

As shown in Table 3 and Fig. 1, cytoplasm of epithelial lining cells of the small intestine emitted strong fluorescence which suggested occurrence of NDV antigen there. Especially in the lower portion of the small intestine the fluorescence and virus titers were higher and more durable. It is of interest to note that specific fluorescence of intestinal mucosa with NDV antigen was positive, but it was less marked, even after the second challenge, when virus reisolation from contents was completely unsuccessful. These findings suggest establishment of surface infection of alimentary mucosa in the primary oral challenge with NDV-Ishii strain, and also the abortive one in the second challenge.

\section{Extended Study of Virus Excretion and Antibody Response in the Primary and Secondary Challenges with NDV-Ishii Strain}

Four chickens were orally infected at 4 weeks of age and rechallenged by the same route with NDV-Ishii on day 44 after the first inoculation. Their fecal excretion of virus, HI and NT serum antibody and NT coproantibody responses were explored in fecal and blood specimens which were collected on days indicated by abscissa of Figs. 2 and 3. 
antigen in the tissue sections of chickens infected orally with NDV-Ishii strain

\begin{tabular}{|c|c|c|c|c|c|c|c|c|c|}
\hline \multicolumn{6}{|c|}{ 1st challenge } & \multicolumn{4}{|c|}{ Day post 2nd challenge } \\
\hline \multicolumn{2}{|c|}{3} & \multicolumn{2}{|c|}{5} & \multicolumn{2}{|c|}{7} & \multicolumn{2}{|c|}{3} & \multicolumn{2}{|c|}{5} \\
\hline$<1$ & $<1$ & $<1$ & $<1$ & 1.5 & $<1$ & $<1$ & $<1$ & $<1$ & $<1$ \\
\hline+ & H & + & - & + & - & $H$ & H & + & - \\
\hline$<1$ & 5.2 & $<1$ & $<1$ & $<1$ & $<1$ & $<1$ & $<1$ & $<1$ & $<1$ \\
\hline+ & IH & + & + & + & - & H & H & $H$ & + \\
\hline$<1$ & 4.4 & $<1$ & $<1$ & $<1$ & $<1$ & $<1$ & $<1$ & $<1$ & $<1$ \\
\hline+ & m & + & + & + & - & $H$ & H & - & - \\
\hline 0.5 & 8.2 & 3.5 & $<1$ & 4.5 & $<1$ & $<1$ & $<1$ & $<1$ & $<1$ \\
\hline+ & H & H & + & $H$ & + & $H$ & $H$ & - & - \\
\hline
\end{tabular}

-: Not specific fluorescence was seen.

,$+ H$ and $\mathrm{H}$ indicate intensities of specific fluorescence.

Fig. 2 is a typical pattern of virus excretion in feces and antibody response shown by one of the four chicken; two others also reacted in the same way. Namely, a four week old chicken was given orally $10^{5.6} \mathrm{TCD}_{50}$ of NDV-Ishii strain at the first challenge, and the second dose of $10^{6.6} \mathrm{TCD}_{50}$ of the same virus was given per os on day 44 after the first inoculation. The titers of excreted NDV in stools reached $10^{7.5}$ and $10^{6.5} \mathrm{TCD}_{50} / \mathrm{g}$ of feces on days 5 and 7 , respectively, after the first challenge, but it was never recoverable after the second dose of virus. HI serum antibody titer began to rise from day 5 or 7 ; its peak was reached about day 10 or 14 , then already decreasing about 3 weeks, and thereafter leveled off at a titer of about $1: 80$. No secondary antibody response was revealed by the secondary challenge with NDV-Ishii strain. NT serum antibody was titrated on days $28,35,54$, and 58 after the first administration, and all the titers were about the same, around $1: 12$ and $1: 32$. NT activity of feces was tested on days indicated on the abscissa of Fig. 2, in the first challenge it was detected on days 28, 35 and 42 in low titers, and its appearence seemed to be accelerated in the second challenge, that is, it was positive on days 10 and 14 after the second challenge and its titers were higher.

Fig. 3 exemplified an atypical feature in virus excretion and antibody response shown by a chicken of the group. In the first challenge, virus appeared in stools later and in a lower titer, and also the peak and plateau of HI serum antibody titers were lower after the first NDV inoculation. It was of interest to have found a little fecal virus excretion 14 days after the second NDV challenge. In accordance with second multiplication of NDV, secondary booster response of HI and NT serum antibodies was noticed 21 days after the second administration of NDV. Fecal NT activity which was tested in the same way as above was found in stool specimens collected at 3 and 4 weeks after the first and second challenge, respectively.

Since this pattern was experienced on only one occasion all through the series of experiments, it is considered as being rather exceptional event that the 


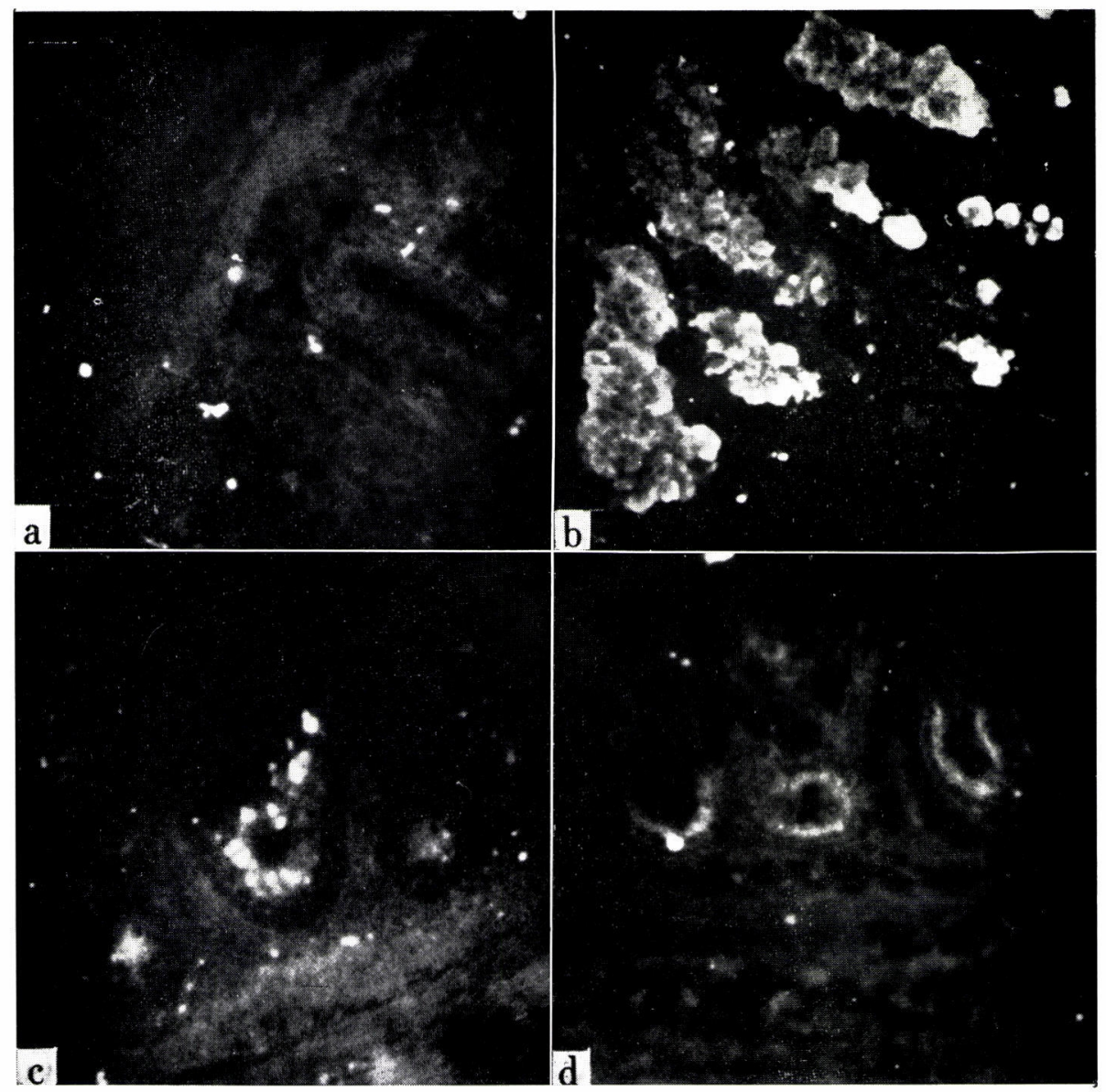

Fig. 1. Indirect fluorescent photomicrograph of frozen sections of the small intestine of NDV infected chickens.

a) Control. No fluorescence is seen.

b) On day 3 post first challenge: Strong fluorescence is observed in mucosal epitherial lining cells.

c) On day 5 post first challenge: The grade of fluorescence is weaker.

d) On day 5 post second challenge: The specific fluorescence is recognizable but weak.

virus can multiply in the intestine after the second feeding.

Two chickens were killed on days 23 and 48 post second challenge and their intestinal tissues and fecal contents were harvested after careful perfusion of the tissue with PBS. The NT titer of tissue extract and fecal content were examined. The results are shown in Table 4.

Nine NT activity positive fecal emulsions which were prepared with PBS as $33.3 \%$ emulsions were pooled, and to it was added an equal volume of saturated ammonium sulfate. The precipitate was dissolved with PBS of $1 / 10$ the original volume, and the solution was further concentrated 10 -foldly by evaporation at 


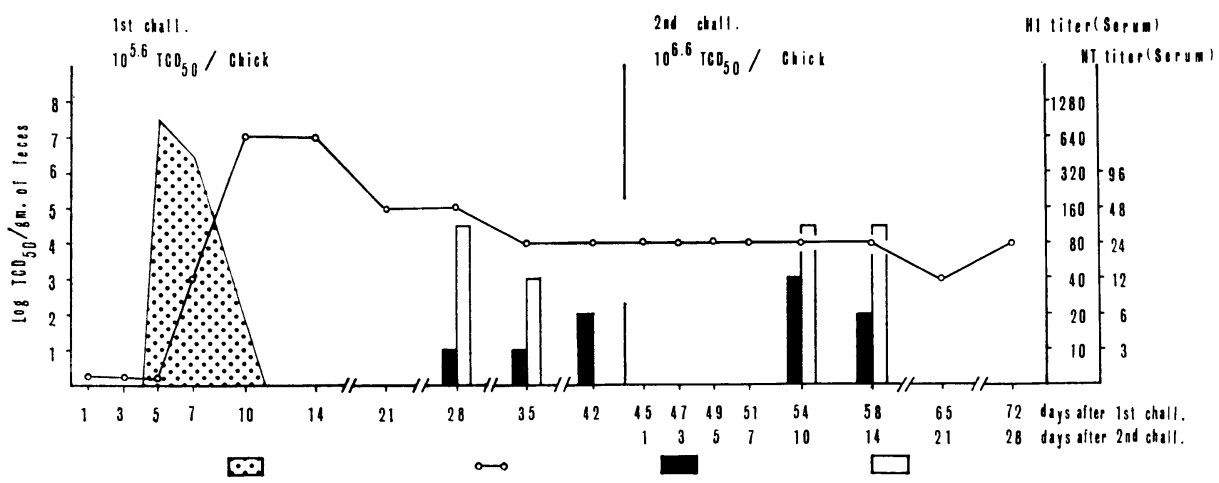

Virus titer(feces)

HI titer (Serun)

NT titer foces

NT titer(Serum)

Fig. 2. Typical pattern of NDV-Ishii excretion in feces, serum and copro-antibody response of a chicken.

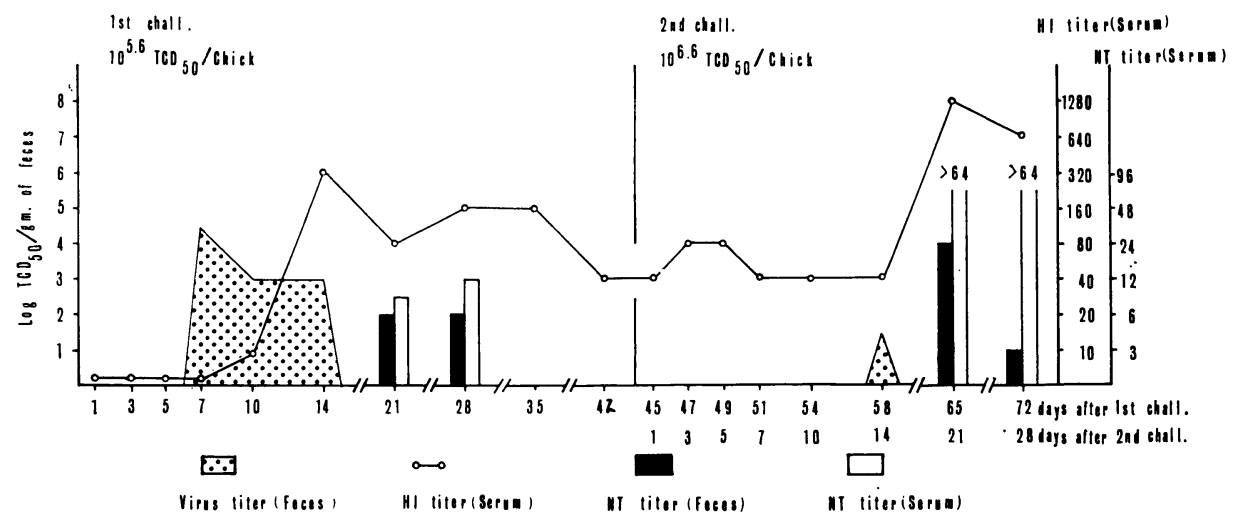

Fig. 3. Atypical pattern of NDV-Ishii excretion in feces, serum and copro-antibody response of a chicken.

Table 4. Results of neutralization test of NDV with supernates of tissue extracts of intestinal tract and feces

\begin{tabular}{|c|c|c|c|}
\hline \multirow{2}{*}{ Intestinal tissue } & \multicolumn{2}{|c|}{$\begin{array}{l}\text { Chicken killed on day } \\
23 \text { post } 2 \text { nd challenge }\end{array}$} & \multirow{2}{*}{$\begin{array}{c}\text { Chicken killed on day } \\
48 \text { post 2nd challenge } \\
\text { Tissue and feces } \\
\text { inclusive }\end{array}$} \\
\hline & Tissue & Feces & \\
\hline Duodenum & $4^{*}$ & - & 4 \\
\hline Small intestine upper portion & 4 & - & 2 \\
\hline Middle portion & - & 4 & 4 \\
\hline Lower portion & - & 8 & 4 \\
\hline Cecum & - & - & ND \\
\hline Rectum & - & $>8$ & ND \\
\hline
\end{tabular}

* Reciprocal dilution of tissue or fecal extract. - : No virus isolation.

ND: Not done. 
room temperature. The concentrate was subjected to immunoelectrophoresis as shown in Fig. 4. However, the exact identification of precipitation was difficult, but it resembled human coproantibody in the immunoelectrophoretic pattern, in that the major component was definitely identified as IgA whereas IgG was present as a minor one. Therefore, it is very likely that the fecal extracts of chickens contain IgA and IgG which relate to the NT activity, but the final decision should be suspended until more data are accumulated on chicken immunoglobulins.

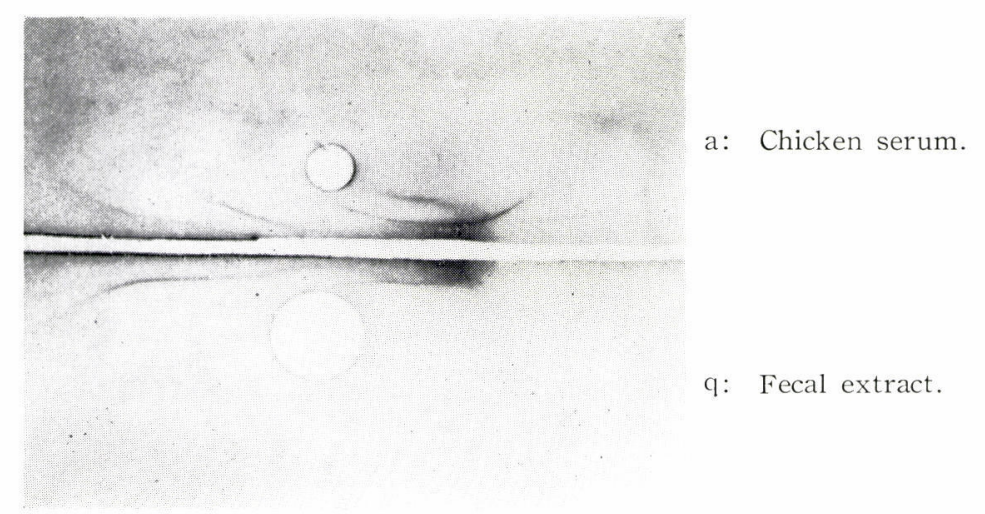

Fig. 4. Immunoelectrophoresis of pooled and concentrated fecal extracts of chickens.

cf. The both fecal extract and chicken serum were precitated with half saturated ammonium sulfate, the precipitates were dissolved in PBS and subjected ot immunoelectrophoresis.

\section{Influence of Intravenous Administration of Antiserum on the Intestinal Infection of NDV}

In order to elucidate the effect of antiserum administered intravenously on the multiplication of NDV in the alimentary tract, $2 \mathrm{ml}$ of hyperimmune chicken serum against NDV of which HI and NT antibody titers were $1: 640$ and $1: 1024$, respectively, were given intravenously to two chickens (group 1) six hr before oral administration of $10^{8.0} \mathrm{TCD}_{50}$ of NDV-Ishii strain and again the same amount of antiserum was given on day 4 to maintain the serum antibody level at $1: 80$ for about 10 days, the time when virus multiplication was supposed to occur in the alimentary tract. Two chickens received anti-NDV serum in the same way but NDV-Ishii was not given: They are the immunization control (group 3). Two other chickens served as unimmunized control, since they merely received NDV-Ishii without passive administration of anti-NDV serum (group 2). Fig 5 illustrates the outcome of the experiment. In two chickens of the immunization control (group 3) the HI serum antibody level was kept through out at about $1: 80$ to $1: 160$ for ten days. Two unimmunized control chickens revealed fecal NDV excretion on days 1, 3 and 5, and spontaneous HI antibody rise was observed one week after the inoculation.

No difference was found in fecal NDV excretion between groups 1 and 2, in 

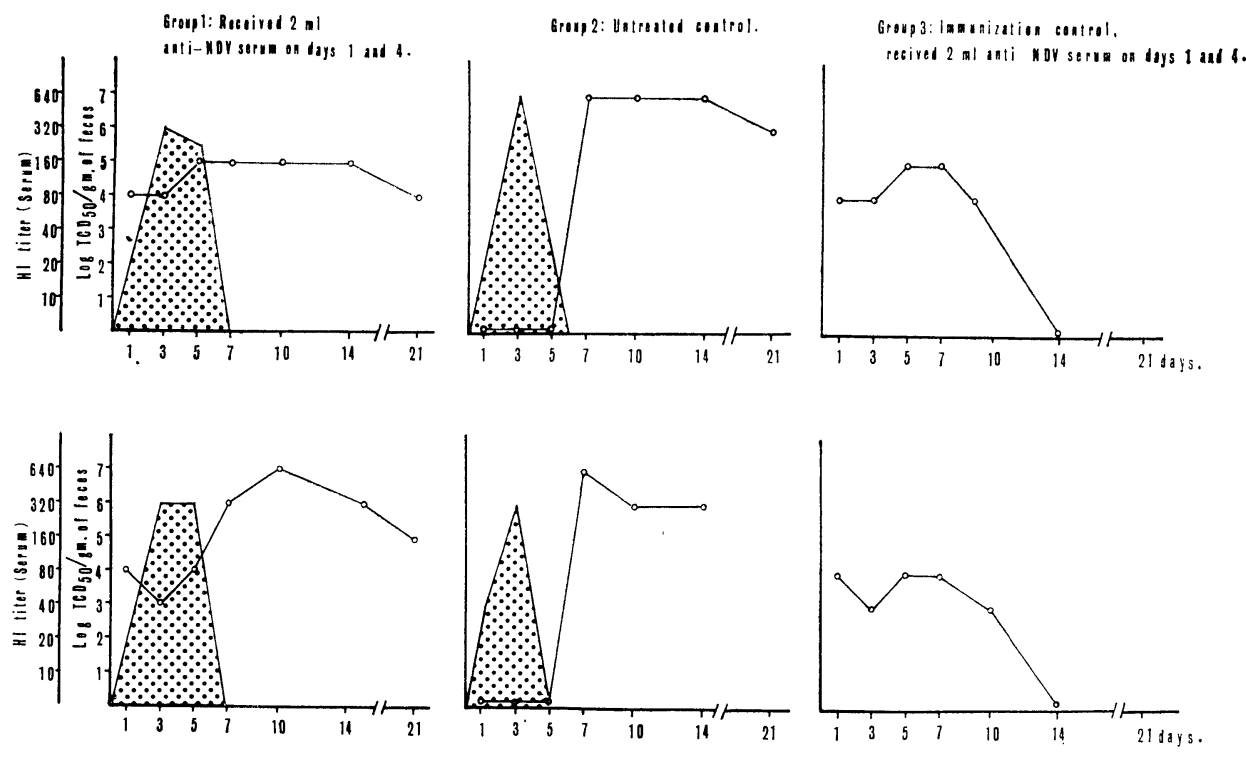

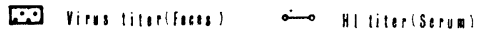

Fig. 5. Influence of passively administered anti NDV chicken serum on NDV multiplication in intestinal tract with matched controls.

spite of the fact that chickens of group 1 maintained the antibody level at $1: 80$ from the beginning. Consequently, it was concluded that passive immunity of such a grade was not able to establish the alimentary tract resistance to feeding of NDV.

\section{Influence of Thymectomy and/or Bursectomy on the Intestinal Infection and Immunity Conferred by NDV}

It is well known that thymus and Bursa Fabricius have great influence on the development of cellular and humoral immunity in birds. Therefore, the effect of thymectomy and/or bursectomy on the alimentary tract infection and immunity with NDV in chickens was investigated.

Chickens whose thymus and/or bursa had been surgically extirpated one day after hatching received on the next day $650 \mathrm{r}$ of $r$ ray irradiation using $\mathrm{Co}^{60}$. Consequently, there were three groups, being designated $\mathrm{T}_{\mathrm{x}}-\gamma$ (thymectomy $+\gamma$ ray-irradiation), $\mathrm{B}_{\mathrm{x}}-\gamma$ (bursectomy $+\gamma$ ray-irradiation) and $\mathrm{T}_{\mathrm{x}} \mathrm{B}_{\mathrm{x}}-\gamma$ (thymectobursectomy $+r$ ray-irradiation) groups.

Other chickens who were sham-operated on thymus and bursa and received $\gamma$-ray were designated as $\gamma$-group, and also several chickens were left as untreated control being called $\mathrm{C}$ group. Each group was composed of three chickens.

All the chickens were orally challenged with NDV-Ishii strain as described before first at 4 weeks of age and then 4 weeks after the first challenge. Fecal NDV excretion and HI serum antibody kinetics were investigated on each chicken.

Fig. 6 (a) illustrates the results of the experiment on $\mathrm{C}$ and $r$-group of chickens. 

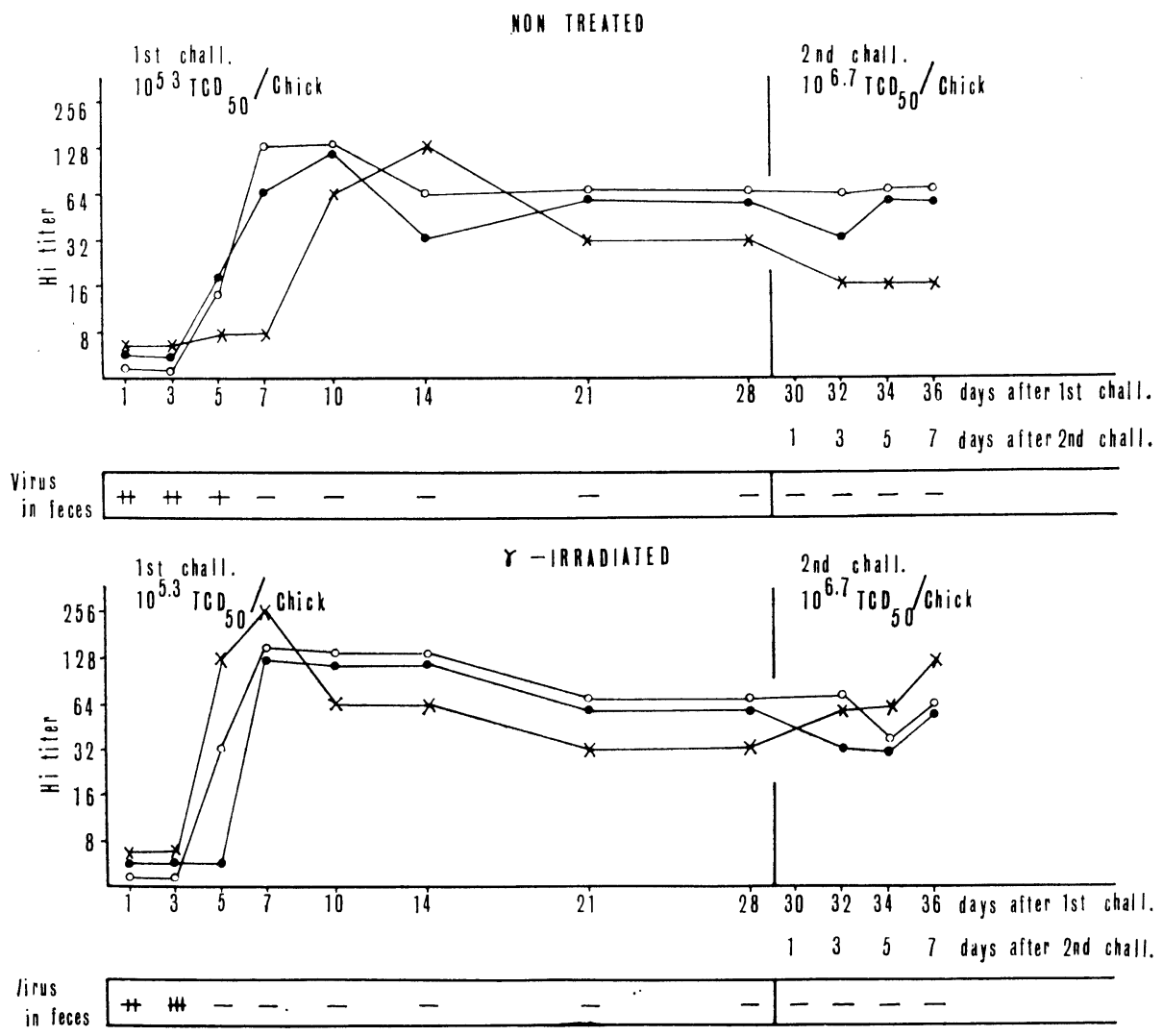

Fig. 6(a). NDV excretion in feces and HI antibody response of untreated (C-group) and $\gamma$-irradiated groups ( $\gamma$-group).

Number of + symbol means number of chickens that NDV-Ishii was recovered from on the indicated day. - symbol means no recovery of NDV.

The picture of antibody response and fecal NDV excretion was completely identical with that obtained in the previous experiments. Namely, alimentary tract resistance against NDV appeared, and no secondary HI antibody response was found in any of the chickens after the second challenge.

Fig. $6(\mathrm{~b})$ are composed of two groups of chickens, $\mathrm{T}_{\mathrm{x}}$ - and $\mathrm{B}_{\mathrm{x}}-\boldsymbol{\gamma}$ groups. The upper pattern of $\mathrm{T}_{\mathrm{x}}-\gamma$ chickens is identical with that of the controls shown in Fig. 6 (a). On the other hand, HI serum antibody developed only poorly in $\mathrm{B}_{\mathrm{x}}-\gamma$ group of chickens: one of the three chickens developed HI antibody on day 10 after the first challenge and it gradually rose up to $1: 32$ or $1: 64$; the other two kept a lower level of antibody during 4 weeks after the first challenge which rose up to $1: 32$ after the second challenge. NDV was reisolated either in the first or in the second challenge. NDV was reisolated either in the first or in the second challenge.

Fig. 6 (c) shows the results of $T_{x} \cdot B_{x}-\gamma$ group and untreated control chickens 

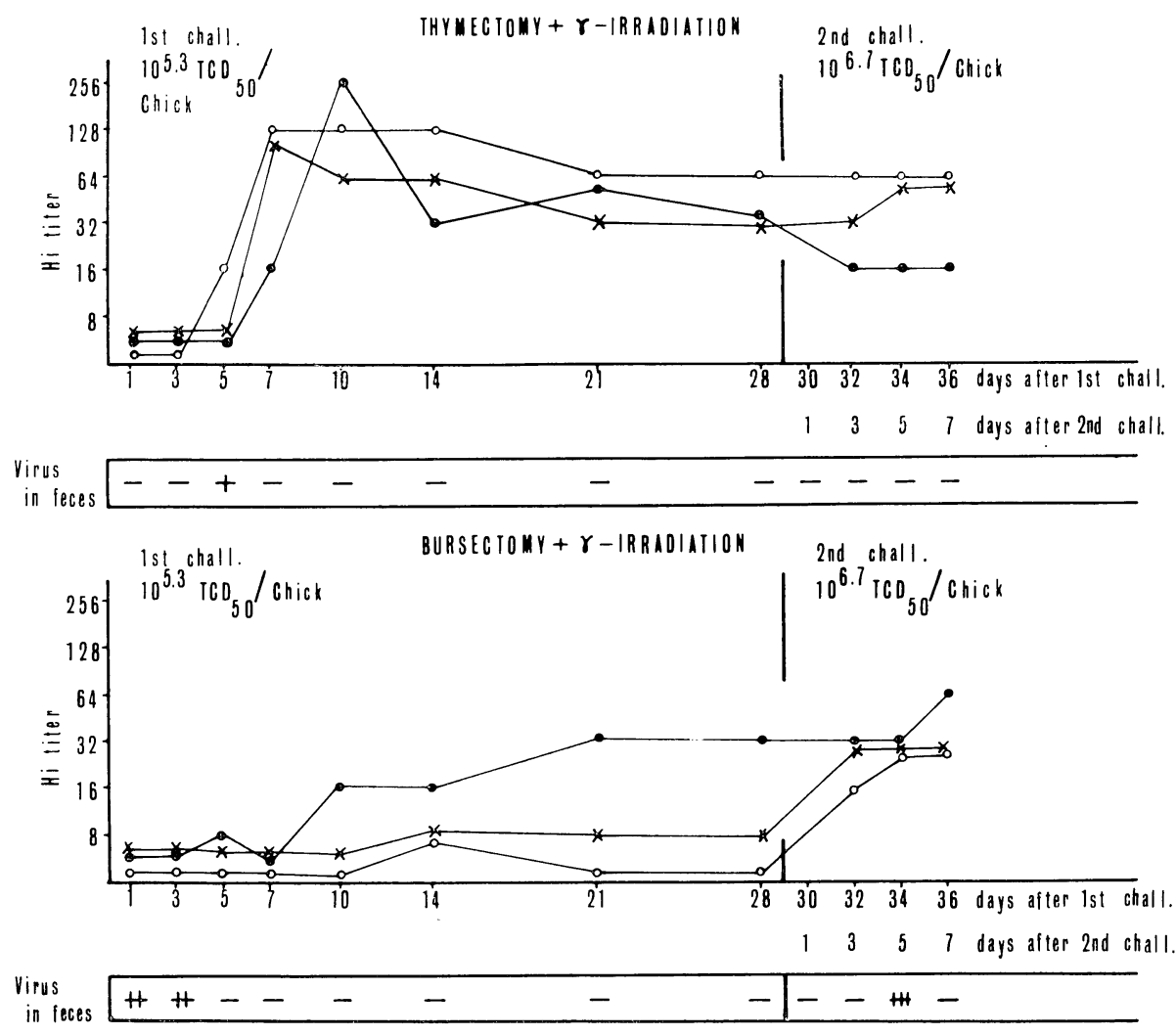

Fig. 6(b). NDV excretion in feces and HI antibody response of thymectomized and $\gamma$-irradiated $\left(\mathrm{T}_{\mathrm{x}}-\gamma\right)$ group and of bursectomized and $\gamma$-irradiated $\left(\mathrm{B}_{\mathrm{x}}-\gamma\right)$ group.

Number of + symbol means number of chickens that NDV-Ishii was recovered from on the indicated day. - symbol means no recovery of NDV.

after the second challenge.

$\mathrm{T}_{\mathrm{x}} \cdot \mathrm{B}_{\mathrm{x}}-\gamma$ group of chickens revealed a severe unresponsiveness of HI serum antibody after the first challenge, but HI antibody reached a titer of about $1: 32$ or 1:64 after the second feeding. NDV was reisolated from feces taken immediately after the first and second administrations. The second challenge controls just confirmed the validity of the second feeding.

It is of great significance that the alimentary tract resistance failed to appear in $\mathrm{B}_{\mathrm{x}}-\boldsymbol{\gamma}$ and $\mathrm{B}_{\mathrm{x}} \cdot \mathrm{T}_{\mathrm{x}}-\boldsymbol{\gamma}$ groups of chickens, but it was maintained by thymectomized chickens.

Immunoelectrophoresis of chickens sera obtained 2 weeks after the primary feeding revealed no distinct difference in $\mathrm{T}_{\mathrm{x}} \boldsymbol{\gamma} \boldsymbol{\gamma}$ and $\gamma$ groups of chickens from normal controls, but production of $\operatorname{IgG}$ and $\operatorname{IgA}$ was apparently suppressed in $B_{x}-\gamma$ chickens and the tendency was much more pronouced in $B_{x} \cdot T_{x}-\gamma$ chickens as shown in Fig. 7.

All the chickens were autopsied 2 weeks after the second challenge ; the spleen 

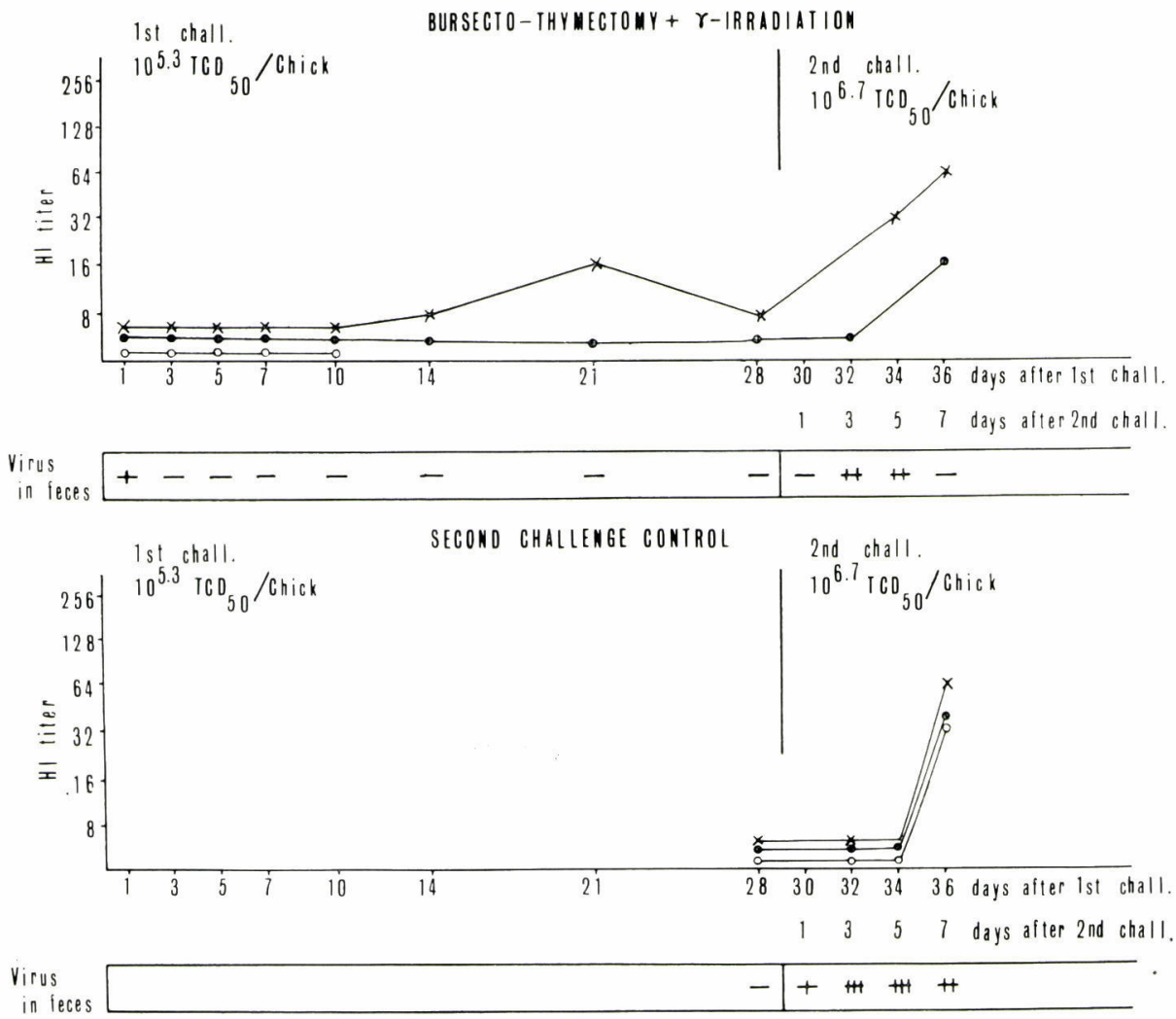

Fig. 6(c). NDV excretion in feces and HI antibody response of bursectothymectomized and $\gamma$-irradiated $\left(B_{x} \cdot T_{x}-\gamma\right)$ group and of the second challenge control.

Number of + symbol means number of chickens that NDV-Ishii was recovered from on the indicated day. - symbol means no recovery of NDV.

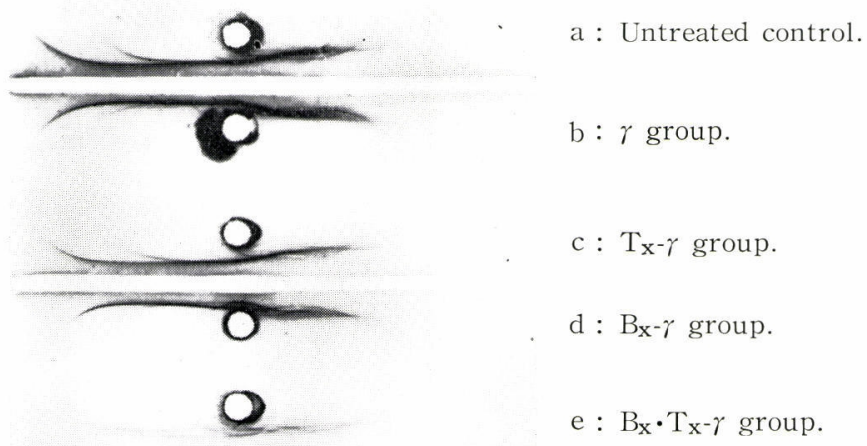

Fig. 7. Immunoelectrophoresis of sera from normal untreated, $T_{\mathrm{X}}-\gamma, \mathrm{B}_{\mathrm{X}}-\gamma$ and $\mathrm{B}_{\mathrm{X}} \cdot \mathrm{T}_{\mathrm{X}}-\gamma$ groups of chickens. 
and small intestinal tissues were histologically examined. The spleens of $B_{x}-\gamma$ and $B_{x} \cdot T_{x}-\gamma$ groups were smaller, lymph follicles in the white pulp were mostly composed of reticulum cells and devoid of large lymphocytes, but no distinct difference from the normal control was found in those of $\gamma$ and $\mathrm{T}_{\mathrm{x}}-\gamma$ groups. When compared with lymph follicles in the intestinal wall mucosa, it was hard to get a distinct difference due to individual variability, but there was a tendency that $\mathrm{B}_{\mathrm{x}}-\gamma$ and $\mathrm{B}_{\mathrm{x}} \cdot \mathrm{T}_{\mathrm{x}} \boldsymbol{\gamma}$ groups of chickens showed poor development of lymph follicles, particularly there were few with germinal center. Generally speaking, the development of lymph follicles in the intestinal wall mucosa was not so poor in those chickens as we expected beforehand. There could have been a recovery of the lymphoid cell system, and it seemed to be supported by the fact that HI antibody production recovered to a certain extent with days elapsing after bursectomy.

It was hard to find any change in number and quality of cells existing in the lamina propria of the intestinal wall of the bursectomized chickens.

\section{DISCUSSION}

In the first part of our study we confirmed that avirulent NDV-Ishii strain had a special characteristic to multiply well in the epithelial lining cells of the intestinal mucosa ; namely, it caused surface infection there, when it was administered by the oral route. As indicated, we demonstrated the occurrence of coproantibody and establishment of local resistance against refeeding of NDV. And no secondary response of HI antibody was seen except in one chicken which had a little fecal excretion of NDV and showed a booster antibody rise. The results indicate that the feeding of NDV-Ishii establishes a strong immune barrier in the intestinal tract. And it is highly likely that the virus reaching it in the secondary feeding can not invade beyond the immune barrier to stimulate the lymph apparatus for secondary serum antibody response. Serum antibody came up as early as the first week, but the NT activity of feces, probably coproantibody, appeared as late as 4 weeks or more after the primary feeding of NDV-Ishii. A similar tendency was observed by us in human coproantibody which appeared 40 days after the feeding of homotypic virus (Kawakami et al., 1966), but earlier appearance of $\operatorname{Ig}$ A coproantibody was suggested by the experiment of Keller et al. (1968) in which the antibody was dissociated from the virus by lowering the $\mathrm{pH}$ (Keller and Dwyer, 1968).

Indirect fluorescent antibody staining revealed that the alimentary tract infection with NDV-Ishii was a sort of surface infection, namely, the epithelial lining cells of intestinal mucosa emitted strong specific fluorescence on days 3 and 5 after the primary feeding, and a rather weaker and less durable reaction was seen after the secondary administration. And NDV was isolated from feces in the former but no virus was recovered in the latter cases.

The main purpose of our experiments was to elucidate the nature of local resistance which appeared in the virus infection of the alimentary tract. There are two schools of thought on the alimentary tract resistance: One considers that the humoral immunity plays a role (Lipton and Steigmann, 1963, Kawakami et al., 1966, Kono et al., 1966) and the other is trying to ascribe it to the cellular 
immunity (Sabin, 1959a). The above finding that specific fluorescence of the mucosal epithelial cells appeared in the secondary infection without virus excretion may imply that susceptible cells appear anew because of their rapid turnover but the newly synthesized NDV is neutralized by local antibody. In other words, the finding seems to support the former hypothesis and the possibility that the cells per se hold immunity is hard to conceive. Since Celzayed et al. (1967) demonstrated IgA accumulation in the apical cytoplasm of rectal mucosa epithelial cells, neutralization may occurr within the cytoplasm.

Our last experiment using thymectomized and/or bursectomized $\gamma$ ray irradiated chickens seems to offer further support to the humoral immunity hypothesis. According to Cooper et al. (1966) bursa-dependent lymphoid system governs the immunoglobulin producing system, and the thymus-dependent lymphoid system controls the cellular immunity. The results show that thymectomy alone has little influence on the immunity of the alimentary tract against NDV; on the other hand, bursectomy exerts a profound influence on antibody production, and thus alimentary tract resistance against NDV is not established 6 weeks after the first feeding of NDV-Ishii.

In our unpublished experiment, we confirmed the occurrence of alimentary tract resistance and appearance of coproantibody in patients with ataxia teleangiectasia after feeding of Sabin type 2 vaccine but, on the other hand, they had symptomes showing a failure of cellular immunity, that is, absence of delayed hypersensitivity, elongated survival of allografts and so on (Kono et al., unpublished data). Therefore, it also seems to support the concept that the thymus-dependent lymphoid system has nothing to do with the alimentary tract resistance to enterotropic virus infection.

However, circulating antibody seems to have little effect on the alimentary tract resistance according to our experiment III and other studies of poliovirus infections (Sabin, 1959a), although it would be able to contribute a little, if circulating antibody titer be exceedingly high (Bodian and Nathanson, 1960).

There have been increasing evidences that $\operatorname{IgA}$ which is produced locally plays an important role in local resistance of various mucosal surfaces to bacterial and viral infections (Bellanti et al., 1965, Tomasi et al., 1965, South et al., 1966, Alford, 1967, Bellanti, 1967, Keller et al., 1969).

We reported that human coproantibody against poliovirus which appeared after feeding of live attenuated poliovirus vaccine was $r$ globulin in nature (Kono et al., 1966), whereas in studies by Keller et al. (1968) and our later unpublished studies (Akao et al., unpublished data) it has become evident that secretory IgA per se is competent for neutralization of poliovirus. The present studies using immuno-electrophoresis reveals that IgA seems to exist in fecal extracts of chickens, although its final characterization is incomplete, because our knowledge on chicken immune globulin is limited. Crabbé et al. (1965) demonstrated that $80 \%$ of plasma cells in the lamina propria of the human intestine were IgA producers, and Eidelman et al. (1968) confirmed the above finding. 


\section{ACKNOWLEDGEMENT}

The authors would like to thank Dr. T. Francis Jr. for his help and comments to prepare the manuscript.

\section{REFERENCES}

AKaO, Y., Kono, R. And Sasagawa, A. (Unpublished data).

ALFORD, R. H. (1976): Neutralizing and hemagglutination-inhibiting activity of nasal secretions following experimental human infection with A2 influenza virus. J. Immunol, 98, 724-731.

Bellanti, J. A., ARtenstein, M. S. AND Buescher, E. L. (1965): Characterization of virus neutralizing antibodies in human serum and secretions. J. Immunol., 94, 344-351.

Bellanti, J. A. (1967): Characterization of human serum and nasal hemagglutinating antibody to Francisella tularesis. J. Immunol., 98, 171-178.

Bodian, D. AND NATHANSON, N. (1960): Inhibitory effect of passive antibody on virulent poliovirus excretion and on immune response in chimpanzees. Bull. Johns Hopkins Hosp., 107, 143-162.

Celzayed, E. A., Kraft, S. C. ANd Fitch, F. W. (1967): Immunoglobulin A: Localization in rectal mucosal epithelial cells. Science, 157, 930-931.

Cooper, M. D., Raymand, D. A., Peterson, R. D. A., South, M. A. And Good, R. A. (1966): The function of thymus system and bursa system in the chicken. J. Exptl. Med, 123, 75-102.

Crabbé, P. A., Carbonara, A. O. and Heremans, J. F. (1968): The normal human intestinal mucosa as a major source of plasma cells containing $\gamma$ A-immunoglobulin. Lab. Invest. 14, 235-248.

EIDELman, S. AND DAVIS, S. D. (1968): Immunoglobulin content of intestinal mucosal plasma-cells in ataxia telangiectasia. Lancet, 1, 884-886.

GODFREDSEN, A. (1960): Failure to demonstrate poliovirus-neutralizing antibodies in stools. Lancet, 2, 292-293.

Kawakami, K., Tatsumi, H., Tatsumi, M. And Kono, R. (1966): Studies on poliovirus coproantibody. 1. Neutralizing antibodies of children following Sabin oral poliovirus. Am. J. Epidemiol., 83, 1-13.

KELlER, R. AND DWYER, J. E. (1968): Neutralization of poliovirus by IgA coproantibodies. J. Immunol., 101, 192-202.

Keller, R., DWyer, J. E., OH, W. AND D'Amodio, M. (1969): Intestinal IgA neutralizing antibodies in newborn infants following poliovirus immunization. Pediatrics, 43, 330-338.

KoHN, A. (1959): The role of the alimentary tract and spleen in Newcastle disease. Am. J. Hyg., 69, 167-176.

Kono, R., Ikawa, S., YaOI, H. JR., Hamada, C., Ashihara, Y. and Kawakami, K. (1966): Studies on poliovirus coproantibody. II. Characterization of neutralizing substance in fecal extracts. Am. J. Epidemiol., 83, 14-23.

Kono, R., AKaO, Y., Sasagawa, A. AND Goya, O. (Unpublished data).

Lipton, M. M. AND Steigman, A. J. (1963): Human coproantibody against polioviruses. J. Infect. Dis., 112, 57-66.

Peterson, R. D. A., Burmester, B. R., Fredrickson, T. N., Purchase, H. G. AND GooD, R. A. (1964): The effect of bursectomy and thymectomy on the development of visceral lymphomatosis in chicken. Nat. J. Cancer Inst., 32, 1343-1354.

SABIN, A. B. (1959a): Present position of immunization against poliomyelitis with live virus vaccines. Brit. Med. J., 1, 663-680.

SABIN, A. B. (1959b): Characteristics of naturally acquired immunity in poliomyelitis and 
of immunity induced by killed and live virus vaccine. In: Immunity and virus infection. V. A. Najjar editor. John Wiley \& Sons Inc. N. Y., 211-232.

ScheidegGer, J. J. (1955): Une micro-methode de l'immunoelectrophrese. Internat. arch. allergy and appl. Immunology, 7, 103-101.

ShimizU, F., KAWAmura, H. AND TsubahaRA, H. (1966): Recovery of wild avirulent Newcastle disease virus and its characterization. Research Rep. Animal Hygine Inst., 52, 1-9. (In Japanese).

South, M. A., Cooper, M. D., Wollheim, F. A., Hong, R. AND Good, R. A. (1966): The $\operatorname{IgA}$ system. I. Studies of the transport and immunochemistry of $\operatorname{IgA}$ in the Saliva. J. Exptl. Med., 123, 615-627.

Tomasi, T. B., TAN, E. G., Solomon, A. And Prendergast, R. A. (1965): Characteristics of an immune system common to certain external secretions. J. Expt1. Med., 121, 101-121. 